\title{
CRIOULIDADE, COLONIALIDADE E GÉNERO: AS REPRESENTAÇÕES DE CABO VERDE
}

\author{
Eurídice Furtado Monteiro \\ Universidade de Cabo Verde, Praia, Cabo Verde
}

\begin{abstract}
Resumo: Este artigo analisa as representações do arquipélago de Cabo Verde. A complexidade das relações de poder e subordinação será observado a partir de uma perspectiva feminista pós-colonial contextualizada em termos geográficos, históricos e culturais, considerando a intersecção entre as classificações de classe, género e raça. Este trabalho é uma crítica das representações hegemónicas de Cabo Verde e da estratégia de silenciar a violência do sistema histórico colonial.

Palavras-chave: Género; Raça; Crioulização e colonialidade.
\end{abstract}

\section{Introdução}

O arquipélago de Cabo Verde tem suscitado um intenso debate, tanto quanto ao pensamento colonial português, como quanto ao imaginário mestiço cabo-verdiano. A partir da década de 1930, os ideólogos coloniais e a elite insular foram disseminando uma série de premissas que vieram robustecer uma ideia de anterioridade da nação crioula em relação ao Estado soberano no arquipélago. Evidentemente, no decurso da história, para a sustentação da fantasia crioula, foram fundamentais tanto as estratégias de identificação como a função do aparelho burocrático-administrativo. Isso tem engrossado o debate contemporâneo sobre as diferentes perspectivas identitárias.

Torna-se, assim, importante empreender uma análise crítica a partir dos estudos póscoloniais e estudos feministas. Por isso, é inevitável e imprescindível examinar a matriz da relação colonial patriarcal que conforma as representações do arquipélago no intuito de, por um lado, examinar os dispositivos discursivos acerca do produto cultural do encontro colonial e, por outro, de proceder a uma dissecação das tentativas de silenciamento do processo histórico de crioulização. Por outras palavras, o exercício consiste em trazer ao debate o impacto e as implicações desse processo histórico na própria situação das

cC) (i) Esta obra está sob licença Creative Commons. 
mulheres. O que é útil destacar sobre os momentos fundacionais - primeiro da origem comum e depois da narração da nação crioula - é que: 1) os dispositivos discursivos, em termos de enunciação, fundaram-se numa matriz colonial patriarcal ou numa lógica de ruptura com a mesma; 2) os relacionamentos raciais e sexuais foram também políticos, estribados num sistémico e histórico poder desigual dos pares da interação. Este artigo questiona, pois, as impressões e explicações culturalistas fornecidas nos períodos claridoso, anticolonial e pós-colonial. Trata-se, portanto, de indagar algumas abordagens sobre a conformação e reconfiguração político-identitária em Cabo Verde.

\section{O colonialismo português em Cabo Verde}

\section{Senhor-Pai-Europa e Escrava-Mãe-África: a invenção de Cabo Verde}

Os estudos pós-coloniais e os estudos feministas inauguraram um novo campo analítico que permite repensar o sistema histórico do colonialismo e pós-colonialismo, no caso cabo-verdiano, através de uma abordagem que esteja atenta às relações de poder, dentro e além das fronteiras de género, classe e região. Isto não só implica uma compreensão do sistema histórico que permitiu primeiramente a gestação da sociedade insular, como requer uma desconstrução das narrativas dominantes que possibilitaram posteriormente a invenção de Cabo Verde como um arquipélago de crioulidade, cuja narração se iniciou no tempo colonial português, ancorado no imaginário luso-tropical.

Admitindo, desde logo, que as ilhas de Cabo Verde estavam desertas quando do seu achamento, o denominado "encontro» entre povos e culturas europeias e africanas (cf. Manuel FERREIRA, 1985; Isabel CALDEIRA, 1993; llídio do AMARAL, 2001; Luís ALBUQUERQUE, 2001; José Carlos Gomes dos ANJOS, 2002; Gabriel FERNANDES, 2006), iniciado no século XV no solo cabo-verdiano, marcou um propalado processo histórico de crioulização, relatado como um caso singular no quadro das antigas colónias portuguesas em África. Efetivamente, essa experiência socio-histórica (cf. Charles BOXER, 1977; 1981; 1988; Elisa ANDRADE, 1996; Marc FERRO, 1996; Elikia M'BOKOLO, 2003; 2007; David BIRMINGHAM, 2004) foi narrada a partir do ponto de vista colonial, i.e., da imaginação colonial portuguesa (Maria Paula MENESES; Margarida Calafate RIBEIRO, 2008, p. 9). Em termos restritos, o presumível impulso aventureiro de homens brancos europeus sobrepôs-se à suposta passividade de mulheres escravas negras africanas. Tal narração reforçou a memória da expansão europeia e da história colonial, silenciando múltiplas violências imperiais (cf. Bartolomé de LAS CASAS, 1990; Fernando GIL; Hélder MACEDO, 1998; Frantz FANON, 2002; Boaventura de Sousa SANTOS, 2006).

Em termos funcionais, no particular contexto cabo-verdiano, com a penetração colonial começou a delinear-se o desequilíbrio nas relações de poder, de género, classe e raça, comprovado através das condições socioeconómicas (António CORREIA E SILVA, 1996, p. 41; Maria Emília Madeira; SANTOS; Iva CABRAL, 2001), pelo controlo administrativo e pelas lutas políticas decorridas no tempo colonial (Zelinda COHEN, 2001; 2007; Iva CABRAL, 2002; Ângela DOMINGUES, 2001). Registava-se, inevitavelmente, uma interpenetração do sistema colonial e do sistema patriarcal. A virilidade imperial ou a hipermasculinidade do Colonizador alcançou uma proporção alarmante, por fixar a Colónia e o Colonizado como meros objetos efeminizados e racializados, estabelecendo a diferença colonial. A autoridade colonial impunha, por inflexão, a dupla lógica de inferiorização. Assim, tal como o racismo colonial, também o sexismo colonial se concebia como mecanismo de dominação. Por conseguinte, esta dupla forma de discriminação acentuaria a marca colonial nas ilhas de Cabo Verde, embora fossem marcadas por um tipo de colonização e povoamento fragmentado e fragilizado

984 Estudos Feministas, Florianópolis, 24(3): 983-996, setembro-dezembro/2016 
devido à distância a que este arquipélago se situava do reino (em comparação com os arquipélagos europeus dos Açores e da Madeira que igualmente se encontravam sob o domínio da metrópole), às condições climáticas e à exiguidade dos recursos naturais (llídio Cabral BALENO, 2001; CORREIA E SILVA, 2002). Não obstante, a situação geográfica do arquipélago promoveu a ocupação e utilização do território como placa giratória nas antigas rotas transatlânticas do tráfico negreiro (CORREIA E SILVA, 1996; 2001 a; 2001 b; António CARREIRA, 2000; Maria Manuel Ferraz TORRÃO, 2001a; 2001b; João LOPES FILHO, 2006).

\section{Ainda a retórica da excepcionalidade cabo-verdiana?}

Indubitavelmente, tem sido revelado que o arquipélago cabo-verdiano vivenciou uma experiência histórica peculiar que teria influenciado decisivamente o processo de construção da identidade individual e coletiva, bem como a estruturação do campo de interação entre o povo das ilhas, a potência colonial e os restantes povos africanos colonizados (FERNANDES, 2002, p. 11). Gabriel Fernandes (2002) ressalta o facto do espaço sociopolítico cabo-verdiano ter sido alvo, desde os primórdios da colonização, e mais intensamente a partir do século XIX, de sucessivas discussões em torno da identidade do povo das ilhas de Cabo Verde e do estatuto a ser atribuído ao arquipélago, questão frisada e documentada por Manuel Brito-Semedo (2006). Numa perspectiva crítica em relação à questão da mestiçagem, defendida pela elite intelectual claridosa, entre os anos de 1936-1960, José Carlos Gomes dos Anjos (2002) considera Cabo Verde como um caso típico de invenção da identidade nacional mestiça. É, portanto, um contexto para constatar que a expansão colonial extravasou os limites do económico e do político', tendo marcado as relações de poder entre homens e mulheres, mas também entre as mesmas. Explica-se, assim, que as representações do arquipélago se ancorem em raízes cultivadas historicamente, mesmo quando adotam novas e diversas configurações².

\section{Mestiçagem, identidade nacional e subalternização das mulheres}

As ideias de Gilberto Freyre que viriam fundar o luso-tropicalismo marcaram, desde a década de 1930, uma mudança expressiva em relação à forma degenerativa como se encarava a mestiçagem. Entre as décadas de 1950 e 1960, o sistema colonial, reforçado pela ditadura salazarista, tinha aproveitado as interpretações de Freyre sobre a identidade brasileira e a ideia da expansão portuguesa como "um empreendimento humanista hibridizante" para justificar, portanto, a contínua ocupação das "Províncias Ultramarinas" e proclamar uma nação plurirracial, pluricultural e pluricontinental (cf. Luís Reis TORGAL, 2002, p. 149; Miguel Vale de ALMEIDA, 2002, p. 32; 2004a, p. 3-5; Margarida Calafate RIBEIRO, 2004, p. 152)3. Isto sucedeu

\footnotetext{
' Ver, por ex., as abordagens de Quijano (2002; 2009), Almeida (2002), Mignolo (2003a; 2003b; 2006), Meneses (2003; 2005; 2007), Santos, Meneses e Nunes (2004), Santos (2006; 2009) e Maldonado Torres (2009).

${ }^{2}$ Para um enquadramento do arquipélago de Cabo Verde, este trabalho conta com os seguintes suportes: As Ilhas de Cabo Verde: Da «Descoberta» à Independência Nacional (ANDRADE, 1996); História Geral de Cabo Verde (HGCV, 2001a; 2001b; 2002); Subsídios para a História de Cabo Verde e Guiné (SENNA BARCELLOS, 2003); Cabo Verde: Formação e Extinção de uma Sociedade Escravocrata (CARREIRA, 2000); África Negra: História e Civilizações (M'BOKOLO, 2003; 2007); O Livro Negro do Colonialismo (FERRO, 2004). Sobre as representações das antigas colónias portuguesas, em África, e a sucessão das leis, dos conceitos e das práticas coloniais, sobretudo, durante os séculos XIX e XX, são fundamentais as interpretações de Meintel (1984), Alexandre (1979; 2000a; 2000b), Almeida (2000), Anjos (2002), Fernandes (2002; 2006), Silvestre (2002), Hernandez (2002), Ribeiro (2004), Trajano Filho (2004), Henriques (2004), Varela (2005), Santos (2006), Matos (2006), Brito Semedo (2006), Costa (2007), Torgal, Pimenta e Sousa (2008), Torgal (2009) e Neto (2009).
} 
precisamente quando começavam a emergir e a sedimentar-se várias movimentações independentistas e se faziam sentir determinadas pressões internacionais contra o colonialismo e algumas simpatias em favor da "autodeterminação dos povos".

Encontrando-se numa situação constrangedora perante o cenário internacional, o regime salazarista concebeu estratégias para camuflar a situação nas antigas colónias. A reforma dos fundamentos político-institucionais e ideológicos constituiu a via encontrada para a manutenção do império (Valentim ALEXANDRE, 2000b, p. 25). Dessa forma, em 1951, depois da revogação do "Acto Colonial" ${ }^{4}$ e da sua integração na Constituição Política da República Portuguesa, "modificando a exterioridade imperial portuguesa, mas não a essência" (RIBEIRO, 2004, p. 152), Freyre iniciou a sua propalada viagem de estudo a Portugal e ao "Ultramar Português", a qual foi patrocinada pelo governo salazarista, visando simultaneamente a explicitação teórico formal do luso-tropicalismo e a sua apropriação político ideológica por parte desse regime (Cláudia CASTELO, 1999, p. 95)

Realce-se que o discurso colonial e a doutrina luso-tropical tiveram uma grande repercussão sobre o discurso claridoso. Aliás, a elite intelectual da época aguardava com elevada expectativa a chegada do sociólogo brasileiro às ilhas de Cabo Verde. Sabe-se que as interpretações iniciais de Freyre já tinham um impacto em Cabo Verde onde, a partir da década de 1930, não se coibia de exaltar a mestiçagem como característica do arquipélago. Estribando-se no luso-tropicalismo como modelo teórico e pragmático, a elite claridosa percepcionava o arquipélago como um exemplo singular e paradigmático de regionalismo cultural europeu e, sendo assim, uma parte essencial do imaginado mundo luso-tropical (João VASCONCELOS, 2004, p. 174; Victor BARROS, 2008, p. 193 194). É evidente que, embora à primeira vista pareça que entre o discurso colonial e o claridoso não havia cumplicidade ideológica, uma análise mais aprofundada permite compreender a intensidade da inter-relação entre os dois discursos (cf. BARROS, 2008)7.

\footnotetext{
${ }^{3}$ Entretanto, permanecia o sentimento de superioridade da cultura portuguesa, sendo necessária a assimilação da "civilização" por parte das "culturas inferiores" (TORGAL, 2002, p. 149 e 161; NETO, 2003, p. 300). ${ }^{4} \mathrm{Em} \mathrm{1822}$, pela primeira vez, tinha sido atribuída a cidadania portuguesa ao arquipélago de Cabo Verde. É relevante recordar que, formalmente, o "Estatuto do Indígena" parecia não incluir a população cabo-verdiana que, com a implantação da República, tinha readquirido a cidadania portuguesa: até 1914, era extensível à Índia e Macau; em 1951, abrangeu Timor e São Tomé e Príncipe; em 1961, Guiné-Bissau, Moçambique e Angola. Cabo Verde almejava o estatuto de arquipélago adjacente, semelhante ao estatuto dos arquipélagos europeus dos Açores e da Madeira. Tal diferença de tratamento político incrementava o sentimento de excepcionalidade de Cabo Verde, quer na metrópole (NETO, 2008) quer no seio da elite letrada colonizada (BARROS, 2008).

${ }^{5}$ Esta foi uma estratégia cosmética de Salazar nos inícios dos anos cinquenta para escapar de qualquer intrusão da comunidade internacional. Antes a designação oficial era de "Colónias" do "Império Colonial Português" (ver "Acto Colonial" de 1930). É importante lembrar que, no quadro da Carta das Nações Unidas, mais precisamente o artigo 73, qualquer potência colonial tinha que passar informações sobre as colónias para as Nações Unidas. $O$ argumento de Portugal era que, sendo a "África Portuguesa" vista como conjunto de "Províncias Ultramarinas", ipso facto parte de Portugal, não havia obrigação de transmitir informações sobre as colónias. Assim, a doutrina luso-tropical foi usada como uma arma diplomática, permitindo esquivar-se de qualquer intrusão nos assuntos ditos internos, na medida em que as colónias passavam a ser tidas por províncias de um Estado soberano, Portugal.

${ }^{6}$ Freyre avançava com a ideia de uma contribuição portuguesa ímpar à civilização mundial, assente na vocação colonial benigna, pacífica e plena de intimidades entre Colonizador e Colonizado (BASTOS, 1998, p. $420 ; 2003$, p. 251).

${ }_{7}^{7}$ Sobre as objeções de Freyre quanto ao carácter luso-tropical do arquipélago de Cabo Verde, e as sucessivas refutações contra as impressões da curta viagem do sociólogo brasileiro, ver Neto (2009, p. 98-111). Importa aqui realçar que, porque revelou a forte presença africana no arquipélago cabo-verdiano ("esse mestiço mais africano que português"), desdenhou os intelectuais claridosos ("gente que, procurando ser europeia, repudia as suas origens africanas") e menosprezou a língua local ("o uso generalizado, pelos ilhéus, de um dialecto"), Gilberto Freyre sofreu duras críticas de intelectuais claridosos e portugueses (cf. NETO, 2009).
}

986 Estudos Feministas, Florianópolis, 24(3): 983-996, setembro-dezembro/2016 
Efetivamente, foi apenas na década de 1950, influenciada pelo contacto com a Casa dos Estudantes do Império e o Centro de Estudos Africanos - ironicamente uma espécie de berço do nacionalismo africano nos espaços de colonização portuguesa -, e ainda pelo processo de "reafricanização dos espíritos", que resultou em um certo movimento de exaltação da cultura africana, o qual rejeitava definitivamente as políticas coloniais de assimilação cultural e tratava o arquipélago como um caso de regionalismo africano. José C. G. Anjos (2003, p. 581) afirma que "todo o processo de construção da identidade nacional cabo-verdiana tem o continente africano como referência, seja para uma afirmação de distanciamento, ou para uma afirmação de proximidade."

Conforme demonstra Fernandes (2002, p. 12), a elite letrada, desde as gerações passadas, procurava, por um lado, assumir-se como idónea mediadora das relações entre naturais da terra e poder colonial - com o objetivo de constituir e de legitimar-se como única interlocutora da metrópole -; e, por outro, consolidar-se como porta voz da população. A ambiguidade entre o cânone oficial e a cultura popular incorporava a diferença colonial objetivada e interiorizada pelo grupo colonizado que, ao mesmo tempo, silenciava e/ou resgatava determinados sujeitos históricos e manifestações culturais. Isto explica que tenha sido, por vezes, silenciado e, outras vezes, denunciado a violência contra o grupo Colonizado e, de modo particular, contra as "colonizadas".

No artigo intitulado "Do Funco ao Sobrado ou o Mundo que o Mulato Criou" (e não o português), Gabriel Mariano (1991 [1959], p. 47-49) assegurava que, em Cabo Verde, "o processo aculturativo desabrochou no florescimento de expressões novas de cultura." Mariano demonstrava assim que "acontecimentos especialíssimos [...] quase que anularam aquilo que é a essência própria da colonização", ou seja, a subordinação integral do grupo Colonizado ao grupo Colonizador ${ }^{8}$. Para o autor, o que explicava a peculiaridade do caso cabo-verdiano talvez fosse "a pouca consistência dos vínculos de subordinação colonial aí estabelecidos", resultante tão-só do "simples e espontâneo fluir dos acontecimentos" (MARIANO, 1991 [1959], p. 47-49)'.

Curiosamente, quando Mariano (1991 [1959], p. 49-53) enaltecia a ascensão social que teria sido propiciada pelo processo de miscigenação no contexto cabo-verdiano, mencionando a ampliação do campo de jurisdição dos sujeitos mestiços, revelava uma visão romântica que não questionava nem a violência histórica nem a apropriação por parte de sujeitos "negros e mestiços" dos ditos elementos e expressões civilizacionais portugueses. Tratava-se de uma conveniente "apropriação unilateral do património cultural socialmente valorizado" (FERNANDES, 2002, p. 85). Também a suposta liberdade de escolha que propalava (MARIANO, 1991 [1959], p. 55) se contradizia com a assimilação como condição para a ascensão social. Deste modo, tal como sugere Homi Bhabha (2002), torna-se crucial admitir o hibridismo, a mímica e a ambivalência como componentes da resistência colonial e da sua superação.

${ }^{8}$ Vasconcelos (2004, p. 175) nota que, apesar da subversão, Mariano colava-se à versão de Freyre, pois "o "mulato" cabo-verdiano de Mariano é tão mulato como o "português» de Freyre", ambos com passado étnico ou cultural.

"É importante recordar que Frantz Fanon assegura que o encontro das "raças branca e negra" levou a uma adoção em massa de um complexo psicoexistencial (FANON, 1975, p. 27-28). Por sua vez, Aimé Césaire (2004, p. 22 23) critica a forma como decorreu o contato entre Europa e África, descodificando as relações de domínio e submissão: "je regarde et je vois, partout où il y a, face á face, colonisateurs et colonisés, la force, la brutalité, la cruauté, le sadisme, le heurt et, en parodie de la formation culturelle, la fabrication hâtive de quelques milliers de fonctionnaires subalternes, de boys, d'artisans, d'employés de commerce et d'interprètes nécessaire à la bonne marche des affaires [...]. Entre colonisateur et colonisé, il n'y a de place que pour la corvée, l'intimidation, la pression, la police, l'impôt, le vol, le viol, les cultures obligatoires, le mépris, la méfiance, la morgue, la suffisance, la muflerie, des élites décérébrées, des masses avilies." 
De acordo com José C. G. dos Anjos (2002, p. 11-12), o darwinismo social e o evolucionismo, dominantes na Europa do século XIX, foram ingredientes implícitos na formulação da identidade mestiça cabo-verdiana durante a primeira metade do século XX. Assim sendo, "a anulação dos signos raciais diacríticos, no plano interno onde todos se fundem numa mestiçagem geral, não significava a ausência de uma concepção racialista." (ANJOS, 2002, p. 11-12). É assim, examinando a questão da mestiçagem como parte final de um longo processo evolutivo, no qual a componente cultural de origem mais africana tenderia a ser progressiva e completamente extinta, que Fernandes (2002, p. 81 89) constata que, afinal, os ditos sujeitos mestiços só começaram a despontar com a requisição de agentes cabo-verdianos para o processo de mediação nas antigas colónias africanas. Luís Batalha (2004, p. 197) refere-se assim a uma elite portuguesa-cabo-verdiana que, nesse tempo, representava o seu papel de intermediário colonial ou quadros subalternos, preenchendo um espaço que não era suficientemente apelativo para a classe média instruída da metrópole, mas que estava fora de alcance dos "pretos e mulatos" locais, motivo pelo qual o relativo nível educacional serviu como um elemento diferenciador para a dita elite cabo-verdiana ${ }^{10}$.

\section{Mulheres sujeitos históricos: Colonizadoras e Colonizadas}

Tendo em conta a escassez de mulheres brancas na colonização, sobretudo nas antigas colónias portuguesas em África, cedo começaram as práticas sexuais e sexistas que auxiliaram o processo de miscigenação. Paradoxalmente, segundo Isabel Castro Henriques (2004), a historiografia portuguesa exalta a capacidade genésica dos portugueses, vistos no cenário colonial como os europeus mais disponíveis para as relações com as mulheres de outras sociedades e culturas, "sem contudo se proceder à elaboração de uma história das relações sexuais e afectivas entre os portugueses e essas muitas Outras que continuam a povoar um certo imaginário português." (HENRIQUES, 2004, p. 343).

No artigo "Entre Próspero e Caliban", inserto no livro A Gramática do Tempo, Boaventura de Sousa Santos (2006) procura ilustrar a prática da ambivalência, da interdependência e da hibridização como uma necessidade da relação colonial portuguesa. De acordo com Miguel Vale de Almeida (2002, p. 31-32; 2004a, p. 5), a miscigenação e a emergência de formas de cultura mista produziram-se como efeitos colaterais, em que os encontros surgiam eivados de relações de poder e não como fruto de uma decisão política, tendo ocorrido num quadro de desigualdade de raça, classe e género e não como resultado de relações horizontais (cf. BOXER, 1988). Para Santos (2006, p. 227), também a miscigenação não foi uma consequência da ausência de racismo, sendo crucial revelar as regras sexistas que "quase sempre deitam na cama o homem branco e a mulher negra, e não a mulher branca e o homem negro."11.

No caso cabo-verdiano, de acordo com a historiadora lva Cabral (2001), nos primórdios da colonização de Cabo Verde, a posição das mulheres na sociedade insular cabo-verdiana

\footnotetext{
${ }^{10}$ A condição de mediador político-cultural tem sido trabalhada por Anjos (2002; 2003; 2004), relacionando não só a posição de produtor cultural, mas também a condição de mediação cultural e política.

${ }^{11}$ No quadro da colonização portuguesa, alguns estudos têm abordado a participação das mulheres (cf. BOXER, 1977). Por exemplo, Henriques (2004, p. 347) constata que: "Os portugueses são, pelo menos nas primeiras fases das operações de reconhecimento, de descoberta e de ocupação, homens sem mulheres. Por isso, não hesitaram eles em utilizar as mulheres Outras." Margarida C. Ribeiro (2007: 20) conclui que "o império se cumpriu pela via masculina, invisibilizando as mulheres." Assim, Timothy J. Coates (1998) contribui para dar visibilidade às mulheres portuguesas colonizadoras, ao analisar a própria participação de 'degredados' e 'órfãs' na colonização (cf. RIBEIRO, 2007). Evidentemente, tal como as missionárias, as órfãs e as prostitutas foram, conforme recorda Margarida C. Ribeiro (2007, p. 21), "as primeiras colonizadoras apoiadas pelo Estado e muito contribuíram para o sedimentar da colonização portuguesa."
} 
não só dependia das famílias de origem, mas ainda do estatuto que detinham em relação ao homem, sendo que elas possuíam direitos, deveres e liberdades diferenciados em consonância com o estado civil: casadas, viúvas ou solteiras. Esta última categoria só abrangia as mulheres da camada pobre e desprovidas de proteção familiar, não incluindo as mulheres brancas. Em 1620, a inexistência de mulheres brancas solteiras no arquipélago levou o rei a decretar que as mulheres que eram degredadas para o Brasil fossem para Cabo Verde, com a finalidade de se extinguir, na medida do possível, a "raça dos mulatos". Quanto à designada "raça dos mulatos", um dos principais meios de ascensão social consistia na sua legitimação, requerida principalmente pelos mesmos com o fito de compensar os "defeitos de sua nascença", para poderem gozar de honras, privilégios e liberdades, bem como da nobreza do seu progenitor. Com isso, adquiriam uma maior capacidade para a ocupação de postos na administração pública e camarária ou para tomarem o hábito religioso. Similarmente, existiam casos de "filhos ilegítimos" contemplados pelos progenitores com doações no testamento. Porém, conforme tem sido realçado em algumas análises históricas, a legitimação e as doações foram em quantidade pouco expressivas, tornando-se menor o número de sujeitos "mulatos" que tiveram a hipótese de ascender às camadas médias e altas da antiga cidade de Ribeira Grande de Santiago. Por isso, apenas a partir da segunda década do século XVII é que teria ocorrido a "mulatização" da elite de Ribeira Grande, devido à crise comercial e ao êxodo da população branca na sequência da perda da posição de entreposto da qual a primeira cidade colonizada desfrutava (CABRAL, 2001, p. 240-245 e p. 252-256; cf. ainda ANDRADE, 1996, p. 42-43).

\section{Arranjos sociais alternativos: transgressão histórica}

[...] em todo esse contexto de conquista e dominação, a apropriação social das mulheres do grupo derrotado é um dos momentos emblemáticos de afirmação de superioridade do vencedor [...].

Quando falamos do mito da fragilidade feminina, que justificou historicamente a proteção paternalista dos homens sobre as mulheres, de que mulheres estamos falando?

"Enegrecer o Feminismo", Sueli Carneiro

É relevante registar que a elite insular, da década de 1930, condicionada tanto pela sua formação ideológica e posição classista como pela repressão estadonovista, tivera dificuldade em introduzir no debate a violência de uma história de escravatura e de colonização ${ }^{12}$. Pelo contrário, os claridosos ficaram entre uma retórica da emancipação e um elogio da colonização, invisibilizando o que sempre dividira a sociedade, i.e., a linha da cor, transmutada em desigualdade classista. $\mathrm{E}$, por isso, numa crítica contra a "dinâmica automutiladora" e o "esquecimento seletivo da África", no ideário claridoso de branqueamento do arquipélago, Gabriel Fernandes (2002, p. 29, 37-39) advertiu para o facto de que se a ligação entre os senhores e as escravas teria constituído como um dos principais eixos de transformação do cenário sociocultural nas ilhas, significaria que o protagonismo das escravas ultrapassava os limites da esfera privada e íntima para atingir o âmago de uma cultura.

Não obstante à visão crítica da funcionalização identitária de Gabriel Fernandes, o autor manteve uma perspectiva heteronormativa em torno do processo identitário, secundando-a com a assunção da presumível fragilidade das mulheres brancas coloniais

${ }^{12}$ Recorde-se que Salazar já havia inaugurado a Colónia Penal do Tarrafal, na ilha de Santiago, em abril de 1936 , para encarcerar os opositores do regime salazarista em Portugal. O campo do Tarrafal encerrou em 1954, tendo sido reaberto em 1961, com a denominação de Campo de Trabalho do Chão Bom, para encarcerar prisioneiros oriundos das antigas colónias portuguesas, após o 4 de fevereiro angolano, que deu início à luta de libertação. 
e a aparente passividade das escravas. Em última instância, esclareceu que, por ter sido uma colonização essencialmente masculina, visto que as mulheres portuguesas foram em menor número, os senhores manteriam uma ligação sexual e afetiva com as suas inimigas/ escravas. Curiosamente, esta tentativa de leitura humanista traçou um cenário bastante romântico, cuja situação faria da "escrava/amante não um ancoradouro dos impulsos sexuais do senhor branco, mas sim uma legítima parceira." E, assim, a escrava seria o "elemento fundante da miscigenação biológica", de igual modo que contribuiria para uma "intensificação da interação sociocultural entre brancos e negros." (FERNANDES, 2002, p. 37-39). Sendo assim, tal como no Brasil, também contrariamente ao que aconteceria nos Estados Unidos, em Cabo Verde não haveria uma segregação étnica. Pelo contrário, haveria uma "tímida mas progressiva aproximação entre os pólos de interação social." Todavia, ficou por abordar a resistência das escravas que preferiram fugir para o interior (FERNANDES, 2002, p. 37-39):

[...] o perfil dos primeiros povoadores: homens brancos, solteiros ou casados, perspicazes e audaciosos o suficiente para driblar as medidas régias e, servindo-se de um ponto estratégico de ancoragem, incrementar seus negócios paralelos com as costas da Guiné. Tendo assumido esse traço de aventura, a colonização praticamente deixou de contar com o elemento feminino (branco), como parcela frágil, para se centrar no varão. Disso terá havido significativa repercussão em toda a estrutura social caboverdiana [...]. O cruzamento do homem branco com escrava negra, seja por constituir elemento fundante da miscigenação biológica, seja por contribuir para a intensificação da interação sociocultural entre brancos e negros, surge como uma das principais máquinas propulsoras da sociedade crioula. A ausência de mulher branca fez da escrava/ amante não um ancoradouro dos impulsos sexuais do senhor branco, mas sim uma legítima parceira, cujo protagonismo suplanta todos os limites de um fórum de relações privado e íntimo para atingir o âmago de uma cultura. [...] a partir do envolvimento com suas escravas, eles foram obrigados a nítidos reajustamentos existenciais que também contribuíram para uma significativa porosidade do quadro de dominação racial em Cabo Verde. Muitos sentiram-se compelidos a alforriar a escrava/amante para não fazer escravo seu próprio filho, resolvendo um grave problema de foro íntimo. Neste cenário, registou-se uma acentuada flexibilização dos mecanismos de conformação e delimitação de posições e condições sociais, traduzida numa tímida mas progressiva aproximação entre os pólos de interação social. [...] a visibilidade do grupo dominado começa a surgir a partir de uma dinâmica de quebra de laços de vassalagem que, paradoxalmente, não se deveu à força do colono, mas à sua fragilização.

Tal contacto racial e cultural entre os senhores e as escravas, para Elisa Andrade (1996), teria-se consagrado menos por causa de um "eventual espírito multirracial que caracterizaria fundamentalmente o colono português" do que devido às "necessidades fundamentais que uniam os dois sexos, em circunstâncias que as mulheres brancas escasseavam." (ANDRADE, 1996, p. 9). Donde, segundo a autora, a conformação de uma interligação complexa entre a dominação colonial e a dominação sexual das mulheres africanas, submetidas largamente ao concubinato. A permissividade e promiscuidade sexual da instituição escravocrata e o estilo de vida senhorial da época teriam tido forte impacto no tecido social cabo-verdiano. No entender do historiador António Carreira (1977, p. 21-32), não só a aventura colonial se configuraria em termos masculinos, como consubstanciaria uma estrutura familiar normativa de matriz patrilinear no arquipélago cabo-verdiano:

[...] em 1513, havia apenas 4 mulheres brancas solteiras! A mulher europeia não emigrava para África; e quando foi com o seu homem fê-lo raramente. Por outro lado, a presença da mulher branca nunca constituiu embaraço para que o homem da mesma etnia fixado 
nas ilhas se ligasse a uma ou mais mulheres africanas. As uniões de homem branco e mulher preta foram, pois, correntes e socialmente aceites de forma geral. Não se olhava à função ou cargo que ele desempenhava. Daí o surto de inúmeros descendentes bastardos de capitães-mores, de governadores, de altos funcionários régios, de ministros da lgreja, etc. [...] Nas ilhas esse tipo de ligações foi mais ou menos aceite pela comunidade sem grande constrangimento, embora em muitos casos as mulheres aspirassem à regularização das situações através do casamento, canónico ou civil. [...] E esse comportamento era, naturalmente, imitado pelos escravos e pelos libertos [...]. A mãesolteira [...] ficou consagrada como realidade sociológica [...]. Pode dizer-se que existe uma poligamia de facto, que não de direito. (CARREIRA, 1977, p. 21-32).

Com relação à população escrava, segundo António Correia e Silva (2001b, p. 324326), "predominavam as uniões livres e de facto, sem qualquer reconhecimento da Igreja." Contudo, a "sociedade tolerava-as sem grande relutância." Desse modo, embora a Igreja condenasse moralmente as "situações de concubinato e mancebia", para os seus senhores "constituíam preciosas oportunidades de engrossar os seus plantéis com novos escravos crioulos." Nesta sequência, segundo o autor, tudo indicaria que na vida prática "as uniões de escravos não só apresentavam um deficit de institucionalização, como também se afiguravam pouco estáveis. Por isso, a célula familiar básica entre os escravos era constituída pela mãe e pelos filhos, sendo o homem variável e marginal." (CORREIA E SILVA, 2001b, p. 324-326). E, sendo assim, "o que figura no registo histórico como unidade familiar identificável e reconhecida é o grupo mãe-filhos. A leitura da descendência entre os escravos faz-se apenas pela linha feminina, contrastando com a filiação acentuadamente patrilinear das famílias dos terratenentes." Portanto, tratariam de "famílias matricêntricas, nas quais a presença do pai é ténue quando não inexistente: 'mater certa, pater incertus'." Assim, na opinião de Correia e Silva, sem ignorar a condição real de vida da massa escrava que "estimulava uniões breves e efémeras", pode concluir-se que este grupo social e histórico, "do ponto de vista das alianças matrimoniais ou meramente conjugais, estava muito longe de possuir um comportamento completamente endogâmico" (CORREIA E SILVA, 2001b, p. 324-326). Daí, o modelo institucional seria a família nuclear ocidental.

Para além disso, António Correia e Silva (2001b, p. 326-329) apontou para o papel central exercido pelas mulheres negras e mulatas em função do uso da sua "sexualidade e afetividade", pese embora o facto dessa mesma relevância ser mitigada em contexto escravocrata e de religiosidade cristã. Para as escravas que não fugiram do cativeiro, esta lógica falocêntrica conduziria a uma mobilidade pessoal e social na subalternidade.

As escravas amancebavam-se ou mesmo casavam-se com homens de posição social superior à delas, a começar pelos antigos escravos tornados livres pela alforria [...]. Em carta de 1701 [...], o rei impõe aos escravocratas a obrigação de venderem as suas escravas aos seus maridos ou pretendentes forros pelo preço determinado pelas justiças da terra [...]. [Contudo], esta lei não era aplicável quando o marido era escravo e a mulher forra [...]. Na sociedade escravocrata as relações sexuais e afectivas são frequentemente utilizadas como um dos mais eficazes 'expedientes' de realização das estratégias de ascensão. Assim, não foram raros os casos das escravas que se amancebaram de forma estável e duradoura com os seus próprios senhores, obtendo deste facto posições materiais e simbólicas importantes no seio da fazenda. [Para além da dimensão puramente individual e sincrónica, tais estratégias de ascensão social das mulheres escravas] continham também objectivos intergeracionais, cujos efeitos eram diferidos no tempo. Dormindo com homens brancos, ricos e poderosos, as escravas 'limpavam' o seu estigmatizante sangue negro, dando origem a crianças mulatas, beneficiadoras do apoio dos pais e, por isso, de maiores possibilidades de virem a libertar-se do cativeiro [...]. Ao dizermos isso apartamo-nos, implicitamente, da ideia 
tradicional, que não vê nestas relações mais do que meras manifestações de domínio sexual do homem sobre a mulher, do escravocrata sobre a escrava, do branco sobre a negra, do sujeito sobre o objecto [...]. [Consequentemente], mesmo entre as malhas apertadas, criadas pela escravatura, algumas das escravas retomavam a iniciativa, utilizando os atributos de inteligência, criatividade, beleza e sedução, [...] [sendo muito importante] descortinar nestes actos de foro íntimo uma lógica social subjacente. (CORREIA E SILVA, 2001b, p. 326-329)

Ao contrário do modelo de comportamento socialmente imposto, o sistema escravocrata teria sido, paradoxalmente, complacente com práticas transgressivas no tocante aos preceitos religiosos e morais. Este processo histórico, a montante e a jusante, teria tido consequências imprevisíveis, traduzidas num pesado fardo para a sociedade em geral e para as mulheres em particular. Por conseguinte, em termos históricos e estruturais, as ilhas cabo-verdianas ficariam marcadas por uma espécie de plasticidade parental, constatando-se no geral, ainda hoje, uma fraca presença da figura do pai na vida familiar e, consequentemente, a subestimação ou relativa valorização do papel e do valor social das mulheres, mormente pela via da sua excessiva sobrecarga no que respeita às responsabilidades relativamente à gestão e manutenção da família.

Desse modo, à guisa de conclusão, para melhor se entender as questões de género e as relações de poder entre homens e mulheres no arquipélago, o foco do debate sobre a sociedade e a cultura centra-se atualmente na abordagem crítica dos papéis sociais e das experiências das mulheres numa sociedade complexa submetida a um tipo ideal patriarcal, corroborado e disseminado, principalmente, nos termos da moral e religiosidade cristã dominante neste espaço insular da costa ocidental africana.

\section{Referências}

ALBUQUERQUE, Luís. "O descobrimento das ilhas de Cabo Verde". In: História Geral de Cabo Verde. 2.ed., v. I. Lisboa e Praia: Instituto de Investigação Científica Tropical e Instituto Nacional de Investigação Cultural, 2001, p. 23-39.

ALEXANDRE, Valentim. "O império africano (séculos XIX-XX): as linhas gerais". In: Valentim Alexandre (Org.). O império africano (séculos XIX e XX). Lisboa: Colibri, 2000, p. 11-28. ALMEIDA, Miguel Vale de. "Crioulização e fantasmagoria", Série Antropologia, 365, 2004a, p. 1-13.

. Outros destinos: ensaios de antropologia e cidadania. Porto: Campo das Letras, 2004b.

"O atlântico pardo. Antropologia, pós-colonialismo e o caso 'lusófono'”. In: BASTOS, Cristiana; ALMEIDA, Miguel Vale de; FELDMAN-BIANCO, Bela. Trânsitos coloniais: diálogos críticos luso-brasileiros. Lisboa: Imprensa de Ciências Sociais, 2002, p. 23-37.

Um mar da cor da terra: raça, cultura e política da identidade. Oeiras: Celta, 2000.

AMARAL, llídio do. "Cabo Verde: introdução geográfica". In: História Geral de Cabo Verde. 2.ed., v. I. Lisboa e Praia: Instituto de Investigação Científica Tropical e Instituto Nacional de Investigação Cultural, 2001, p. 1-39.

ANDRADE, Elisa. As ilhas de Cabo Verde: da "descoberta" à independência nacional (1460-1975). Paris: L'Harmattan, 1996.

ANJOS, José Carlos Gomes dos. "A condição de mediador políitico-cultural em Cabo Verde: Intelectuais e diferentes versões da identidade nacional", Etnografia, v. III (2), p. 273-295, 2004.

"Elites intelectuais e conformação da identidade nacional em Cabo Verde", Estudos Afro Asiáticos, Ano 25, 3, p. 579-596, 2003. 
Intelectuais, literatura e poder em Cabo Verde: lutas de definição da identidade nacional. Porto Alegre e Praia: Universidade Federal do Rio Grande do Sul e Instituto Nacional de Investigação, Promoção e Património Culturais, 2002.

BALENO, llídio Cabral. "Povoamento e formação da sociedade". In: História Geral de Cabo Verde. 2.ed., v. I. Lisboa e Praia: Instituto de Investigação Científica Tropical e Instituto Nacional de Investigação Cultural, 2001, p. 125-177.

BASTOS, Cristiana. "Tristes trópicos e alegres luso-tropicalismos: das notas de viagem em Lévi-Strauss e Gilberto Freyre", Análise Social, v. XXXIII, 146/147, p. 415-432, 1998.

. "Um luso-tropicalismo às avessas: colonialismo científico, aclimatação e pureza racial em Germano Correia". In: RIBEIRO, Margarida C.; FERREIRA, Ana Paula. Fantasmas e fantasias imperiais no imaginário português contemporâneo. Porto: Campo das Letras, 2003, p. 227-253.

BARROS, Victor. "As 'sombras' da Claridade: entre o discurso de integração regional e a retórica nacionalista". In: TORGAL, Luís Reis; Pimenta, FERNANDO Tavares; SOUSA, Julião Soares. Comunidades imaginadas: nação e nacionalismos em África. Coimbra: Imprensa da Universidade de Coimbra, 2008, p. 193-217.

BATALHA, Luís. "A elite portuguesa-cabo-verdiana: ascensão e queda de um grupo colonial intermédio". In: CARVALHO, Clara; PINA, Cabral João de. A persistência da história: passado e contemporaneidade em África. Lisboa: Imprensa de Ciências Sociais, 2004, p. 191 225.

BIRMINGHAM, David. Portugal and Africa. Athens: Ohio University Press, 2004.

BHABHA, Homi. O local da cultura. Belo Horizonte: UFMG, 2007.

BOXER, Charles. A mulher na expansão ultramarina Ibérica (1415-1815): alguns factos, ideias e personalidades. Lisboa: Horizonte, 1977.

O império colonial português (1415-1825). Lisboa: Edições 70, 1981. 988.

BRITO-SEMEDO, Manuel. A construção da identidade nacional: análise da imprensa entre 1877 e 1975. Praia: Instituto da Biblioteca Nacional e do Livro, 2006.

CABRAL, Iva. "Política e sociedade: ascensão e queda de uma elite endógena". In: História Geral de Cabo Verde (HGCV), v. III. Lisboa e Praia: Instituto de Investigação Científica Tropical e Instituto Nacional de Investigação, Promoção e Património Culturais de Cabo Verde, 2002, p. 235326.

"Ribeira Grande: vida urbana, gente, mercancia, estagnação". In: História Geral de Cabo Verde. 2.ed., v. II. Lisboa e Praia: Instituto de Investigação Científica Tropical e Instituto Nacional de Investigação Cultural, 2001, p. 225-273.

CALDEIRA, Isabel. "O afro-americano e o cabo-verdiano: identidade étnica e identidade nacional". In: SANTOS, Boaventura de Sousa (Org.). Portugal: um retrato singular. Porto: Afrontamento, 1993, p. 591-628.

CARNEIRO, Sueli. "Enegrecer o feminismo: a situação da mulher negra na América Latina a partir de uma perspectiva de gênero". In: ASHOKA EMPREENDIMENTOS SOCIAIS; TAKANO CIDADANIA (Orgs.). Racismos contemporâneos. Rio de Janeiro: Takano Editora, 2003, p. 49-58.

CARREIRA, António. Cabo Verde: formação e extinção de uma sociedade escravocrata (1460-1878). 3.ed. Praia: Instituto de Promoção Cultural, 2000.

CASTELO, Cláudia. "O modo português de estar no mundo»: o luso tropicalismo e a ideologia colonial portuguesa (1933 1961). Porto: Afrontamento, 1999.

CÉSAIRE, Aimé. Discours sur le colonialisme. Paris: Présence Africaine, 2004.

COSTA, Sérgio. "Desprovincializando a Sociologia: a contribuição pós-colonial", Revista Brasileira de Ciências Sociais, v. 21(60), p. 117-134, 2006. 
COATES, Timothy J. Degredados e órfãs: colonização dirigida pela coroa no império português (1550-1755). Lisboa: Comissão Nacional para as Comemorações dos Descobrimentos Portugueses, 1998.

COHEN, Zelinda. "Administração das ilhas de Cabo Verde e seu distrito no segundo século de colonização (1560 1640)". In: História Geral de Cabo Verde, 2.ed., v. II. Lisboa e Praia: Instituto de Investigação Científica Tropical e Instituto Nacional de Investigação Cultural, 2001 p. 189-224.

. Os filhos da folha (Cabo Verde - séculos XV-XVIII). Praia: Spleen, 2007.

CORREIA E SILVA, António. "Dinâmicas de decomposição e recomposição de espaços e sociedades". In: História Geral de Cabo Verde (HGCV), v. III. Lisboa e Praia: Instituto de Investigação Científica Tropical e Instituto Nacional de Investigação, Promoção e Património Culturais de Cabo Verde, 2002, p. 1-66.

CORREIA E SILVA, António. "A sociedade agrária. Gentes das águas: senhores, escravos e foros". In: História Geral de Cabo Verde. 2.ed. Vol. II. Lisboa e Praia: Instituto de Investigação Científica Tropical e Instituto Nacional de Investigação Cultural, 2001 b, p. 275-357.

"Cabo Verde e a geopolítica do atlântico". In: História Geral de Cabo Verde. 2.ed., v. II. Lisboa e Praia: Instituto de Investigação Científica Tropical e Instituto Nacional de Investigação Cultural, 2001a, p. 1-16.

Histórias de um Sahel insular. 2.ed. Praia: Spleen, 1996.

"O nascimento do leviatã crioulo: esboços de uma Sociologia Política", Caderno de Estudos Africanos, 1, Jul-Dez, $2001 \mathrm{c}$.

D'ALMEIDA, José Evaristo. O Escravo. Linda-a-Velha: ALAC, 1986.

DOMINGUES, Ângela. "Administração e instituições: transplante, adaptação, funcionamento". In: História Geral de Cabo Verde. 2.ed., v. I. Lisboa e Praia: Instituto de Investigação Científica Tropical e Instituto Nacional de Investigação Cultural, 2001, p. 41-123.

FANON, Frantz. Le damnés de la terre. Paris: La Découverte, 2002. Pele negra, máscaras brancas. 2.ed. Porto: Paisagem, 1975.

FERNANDES, Gabriel. A diluição da África: uma interpretação da saga identitária caboverdiana no panorama político (pós)colonial. Florianópolis: Editora da UFSC, 2002.

FERREIRA, Manuel. A aventura crioula. 3.ed. Lisboa: Plátano, 1987.

FERRO, Marc. História das colonizações: das conquistas às independências (sécs. XIII-XX). Lisboa: Estampa, 1996.

O Livro Negro do Colonialismo. Rio de Janeiro: Ediouro, 2004.

GIL, Fernando; MACEDO, Hélder. Viagens do olhar: retrospecção, visão e profecia no renascimento português. Porto: Campo das Letras, 1998.

HENRIQUES, Isabel Castro. Os pilares da diferença: relações Portugal-África séculos XV-XX. Lisboa: Caleidoscópio, 2004.

LAS CASAS, Bartolomé de. Brevíssima relação da destruição de África. Lisboa: Antígona, 1996.

LOPES FILHO, João. Cabo Verde: Abolição da escravatura - subsídios para o estudo. Praia: Spleen, 2006.

MALDONADO-TORRES, Nelson. "A topologia do ser e a geopolítica do conhecimento: modernidade, império e colonialidade". In: SANTOS, Boaventura de Sousa; MENESES, Maria Paula. Epistemologias do Sul. Coimbra: Almedina, 2009, p. 337-382.

MARIANO, Gabriel. "Do funco ao sobrado ou o mundo que o mulato criou". In: Cultura Cabo-Verdiana: Ensaios. Lisboa: Veja, 1991 [1959], p. 39-63.

MATOS, Patrícia. As côres do império: representações raciais no império colonial português. Lisboa: Imprensa de Ciências Sociais, 2006. 
M'BOKOLO, Elikia. África negra: história e civilizações - até ao século XVIII, Tomo I. Lisboa: Vulgata, 2003

África negra: história e civilizações - do século XIX aos nossos dias. 2.ed. Tomo II. Lisboa: Colibri, 2007.

. "Entrevista", Cabo dos Trabalhos, n. 2, 2007. Disponível em: http://cabodostrabalhos. ces.uc.pt/n2/entrevistas.php. Acesso em 04/06/2016.

MENESES, Maria Paula; RIBEIRO, Margarida C. "Cartografias literárias incertas". In: RIBEIRO, Margarida Calafate; MENESES, Maria Paula. Moçambique: das palavras escritas. Porto: Afrontamento, 2008, p. 9-17.

MENESES, Maria Paula. "Mulheres insubmissas? Mudanças e conflitos no norte de Moçambique". Ex œequo - Revista da Associação Portuguesa de Estudos sobre as Mulheres, n. 17, p. 71 $87,2008$.

"Os espaços criados pelas palavras: racismos, etnicidades e o encontro colonial". In: GOMES, Nilma (Org.). Um olhar além das fronteiras: educação e relações raciais. Belo Horizonte: Autêntica, 2007, p. 55-76.

"Poderes neo-tradicionais e o Estado moderno em Moçambique: as possibilidades da reinvenção do 'tradicional'”. In: Cabral no cruzamento de épocas: comunicações e discursos produzidos no Il Simpósio Internacional Amílcar Cabral. Praia: Alfa Comunicações, 2005, p. 535-546.

"Agentes do conhecimento? A consultoria e a produção do conhecimento em Moçambique". In: SANTOS, Boaventura de Sousa (Org.). Conhecimento prudente para uma vida decente: 'um discurso sobre as ciências' revisitado. Porto: Afrontamento, 2003, p. 683-715.

MIGNOLO, Walter. "El giro gnoseológico decolonial: la contribución de Aimé Césaire a la geopolítica y la corpo-política del conocimiento". In: CÉSAIRE, Aimé. Discurso sobre el colonialismo. Madrid: Akal, 2006, p. 197-221.

Historias locales/diseños globales: colonialidad, conocimiento subalterno $y$ pensamiento fronterizo. Madrid: Akal, 2003a.

"Os esplendores e as misérias da 'ciência': colonialidade, geopolítica do conhecimento e pluri-versalidade epistêmica". In: SANTOS, Boaventura de Sousa (Org.). Conhecimento prudente para uma vida decente: 'um discurso sobre as ciências' revisitado. Porto: Afrontamento, 2003b, p. 631-671.

NETO, Sérgio. "Cabo-verdianidade e luso-tropicalismo: duas visões de Cabo Verde em tempos de Estado Novo", Estudos do Sec. XX - Colonialismo, anticolonialismo e identidades nacionais, 3, 2003, p. 291-319.

"Insularidade, idiossincrasias e imaginação: representações de Cabo Verde no pensamento colonial português". In: TORGAL, Luís Reis; PIMENTA, Fernando Tavares; SOUSA, Julião Soares. Comunidades imaginadas: nação e nacionalismos em África. Coimbra: Imprensa da Universidade de Coimbra, 2008, p. 181-192.

QUIJANO, Anibal. "Colonialidade do poder e classificação social". In: SANTOS, Boaventura de Sousa; MENESES, Maria Paula (Orgs.). Epistemologias do Sul. Coimbra: Almedina, 2009, p. 73-117.

"Colonialidade, poder, globalização e democracia", Novos Rumos, ano 17, n. 37, p. 4-28, 2002. Disponível em: http://www2.marilia.unesp.br/revistas/index.php/ novosrumos/article/view/2192/1812. Acesso em 28/05/2016.

OLIVEIRA, João Nobre de. A Impressa Cabo-verdiana (1820-1975). Macau: Fundação Macau, 1998.

RIBEIRO, Margarida Calafate. África no feminino: as mulheres portuguesas e a guerra colonial. Porto: Afrontamento, 2007. 
Uma história de regressos: império, guerra colonial e pós colonialismo. Porto: Afrontamento, 2004.

SANTOS, Boaventura de Sousa. A gramática do tempo: para uma nova cultura política. Porto: Afrontamento, 2006.

SANTOS, Boaventura de Sousa; MENESES, Maria Paula; NUNES, João Arriscado. "Introdução Para ampliar o cânone da ciência: a diversidade epistemológica do mundo". In.: SANTOS, Boaventura de Sousa. Semear outras soluções: os caminhos da biodiversidade e dos conhecimentos rivais. Porto: Afrontamento, 2004, p. 19-101.

SANTOS, Boaventura de Sousa. "Para além do Pensamento Abissal: das linhas globais a uma ecologia de saberes". In: SANTOS, Boaventura de Sousa; MENESES, Maria Paula. Epistemologias do Sul. Coimbra: Almedina, 2009, p. 23-71.

SANTOS, Maria Emília Madeira; CABRAL, Iva. "O nascer de uma sociedade através do morador-armador". In: História Geral de Cabo Verde, 2.ed., v. I. Lisboa e Praia: Instituto de Investigação Científica Tropical e Instituto Nacional de Investigação Cultural, 2001, p. 371-430.

TORGAL, Luís Reis. “'Muitas raças, uma nação' ou o mito de Portugal multirracial na 'Europa' do Estado Novo", Estudos do Sec. XX-Europa Utopia/Europa Realidade, 2, 2002, p. 149 165.

TORRÃO, Maria Manuel Ferraz. "Actividade comercial externa de Cabo Verde: organização, funcionamento, evolução". In: História Geral de Cabo Verde, 2.ed., v. I. Lisboa e Praia: Instituto de Investigação Científica Tropical e Instituto Nacional de Investigação Cultural, 2001a, p. 237-345.

. "Rotas comerciais, agentes económicos, meios de pagamento". In: História Geral de Cabo Verde. 2.ed., v. II. Lisboa e Praia: Instituto de Investigação Científica Tropical e Instituto Nacional de Investigação Cultural, 2001b, p. 17-123.

VASCONCELOS, João. "Espíritos lusófonos numa ilha crioula: língua, poder e identidade em São Vicente de Cabo Verde". In: CARVALHO, Clara; CABRAL, João de Pina. A persistência da história: passado e contemporaneidade em África. Lisboa: Imprensa de Ciências Sociais, 2004, p. 149-190.

[Recebido em 03/05/2016

e aceito para publicação em 18/05/2016]

Creoleness, Coloniality and Gender: the Representations of Cape Verde

Abstract: This article analyses the representations of the archipelago of Cape Verde. The complexity of power relations and subordination will be observed from a post colonial feminist perspective - contextualized in geographical, historical and cultural terms -, and will consider the intersection between the classifications of class, gender and race. This paper is a criticism of the hegemonic representations of Cape Verde and the strategy of silencing the violence of the historical colonial system.

Keywords: Gender; Race; Creolization and Colonialism. 